\title{
Prognostic significance of the programmed death ligand 1 expression in clear cell renal cell carcinoma and correlation with the tumor microenvironment and hypoxia- inducible factor expression
}

Hayriye Tatli Dogan ${ }^{1 *}$, Merve Kiran², Burak Bilgin ${ }^{3}$, Aydan Kiliçarslan ${ }^{1}$, Mehmet Ali Nahit Sendur ${ }^{4}$, Bülent Yalçin ${ }^{4}$, Arslan Ardiçoglư ${ }^{5}$ Ali Fuat Atmaca ${ }^{5}$ and Berrak Gumuskaya ${ }^{1}$

\begin{abstract}
Background: Clear cell renal cell carcinoma (ccRCC) is the most common renal malignancy. Hypoxia-inducible factors, HIF-1a and HIF-2a, are expressed in the majority of ccRCC. Targeting immune checkpoints with the blockade of PD-1 and its ligand PD-L1 reorganizes T-cell activity in tumor microenvironment and provides important antitumor responses. PD-L1 upregulation has been found to be hypoxia-inducible factor (HIF) dependent. Our aim is to demonstrate the association between PD-L1 and HIF expression and to reveal the role of PD-L1 in prognosis and its association with tumor microenvironment.

Methods: Surgical specimens from 145 patients diagnosed with $C C R C C$, who had undergone radical or partial nephrectomy, were retrospectively analyzed. Immunohistochemistry on tissue microarrays (TMA) was performed to demonstrate expressions of PD-L1, HIF-1a, and HIF-2a in tumor cells and PD-1, CD4, and CD8 in lymphocytes to assess lymphocyte density in tumor microenvironment.

Results: PD-L1 tumor cell expression was detected in 20/125 (13.8\%) cases, which correlated with higher levels of PD-1, CD4, CD8 and HIF-2a expression. Low or high expression of HIF-1a was similar in PD-L1-positive cases. When PD-L1-positive cases were compared with negative ones, there was no significant difference in terms of prognostic factors. However, the number of WHO/ISUP grade 3-4 tumors was significantly higher in PD-L1positive cases than in negative ones.
\end{abstract}

Conclusion: PD-L1 tumor cell expression is strongly associated with increased HIF-2a expression and presence of dense lymphocytic infiltration in CCRCCs. Our findings confirm that PD-L1 positivity is associated with high ISUP nucleolar grade. The association between PD-L1, HIF, and lymphocyte density in tumor microenvironment must be clarified and especially taken into account in combination treatment.

Keywords: PD-L1, PD-1, HIF, Renal cell carcinoma

\footnotetext{
* Correspondence: hayriyetatli@gmail.com

${ }^{1}$ Faculty of Medicine, Department of Pathology, Ankara Yıldırım Beyazıt

University, Ankara, Turkey

Full list of author information is available at the end of the article
}

(c) The Author(s). 2018 Open Access This article is distributed under the terms of the Creative Commons Attribution 4.0 International License (http://creativecommons.org/licenses/by/4.0/), which permits unrestricted use, distribution, and reproduction in any medium, provided you give appropriate credit to the original author(s) and the source, provide a link to the Creative Commons license, and indicate if changes were made. The Creative Commons Public Domain Dedication waiver (http://creativecommons.org/publicdomain/zero/1.0/) applies to the data made available in this article, unless otherwise stated. 


\section{Background}

As one of the leading therapy-resistant malignancies, renal cell carcinoma exhibits poor or no response to hormonal therapy, radiotherapy, and chemotherapy [1]. Clear cell renal cell carcinoma (ccRCC) comprises about 3\% of adult cancer cases and is an aggressive tumor characterized in most cases by the inactivation of the tumor -suppressor gene VHL. The Von Hippel-Lindau protein (pVHL) regulates the hypoxia-inducible factor (HIF), and the loss of the pVHL function causes constitutive stabilization of HIF- $1 \alpha$ and HIF- $2 \alpha$, resulting in the induction of HIF-transcriptional targets [2]. Reportedly, HIF activation is an important oncogenic driving force in ccRCC. In fact, HIF- $1 \alpha$ and HIF- $2 \alpha$ play a crucial role in the tumor growth and tumor progression, respectively [3, 4]. Furthermore, HIF activates genes, which encode proteins associated with angiogenesis and cell -cycle regulation.

The pVHL-HIF-VEGF pathway plays an essential role in angiogenesis and is targeted by anti-angiogenic therapy. Targeted therapies, including vascular endothelial growth factor and the mTOR pathway inhibitors, demonstrate a prolonged progression-free and overall survival rate; no durable response has yet been achieved. In addition, targeted therapies affecting the downstream of the pVHLHIF pathway or mTOR are characterized by toxic side effects. Recently, targeting immune checkpoints has been reported as a novel approach for cancer treatment [5].

The blockage of programmed cell death 1 (PD-1) and its interference with its ligand, programmed death ligand 1 (PD-L1) reorganizes the T-cell activity in the tumor microenvironment and facilitates critical antitumor responses. PD-1 is a cell-surface protein of 288 amino acids, which is an immune inhibitor, and is expressed because of the immunological activation of $\mathrm{PD}-1^{+}, \mathrm{CD} 4^{+}, \mathrm{CD}^{+} \mathrm{T}$ cells, NK cells, B cells, and monocytes [6]. Previously, two PD-1 ligands (PD-L1, also called B7-H1, and PD-L2, also known as B7-DC) have been described. While PD-L1 is expressed in several cells, including resting T cells, B cells, macrophages, dendritic cells (DCs), and vascular endothelial cells, PD-L2 is expressed only in macrophages and DCs [7]. Downregulation of T-cell response is because of the interaction between PD1 and PD-L1-PD-L2 ligand expressed by tumor cells. The inhibition of the PD-1PD-L1 axis increases the T-cell proliferation and cytotoxicity, indicating a promising mechanism to stimulate the antitumor activity of the immune system [8]. In addition, PD-L1, which is expressed in tumor cells, contributes to metastasis and progression, repressing any T-cell-mediated immune response against cancer. Although the PD-L1 expression is a potential predictive biomarker, it also correlates with the worst clinical course in tumors, including renal cell cancers [9-14]. As a result, the need of developing novel therapies for the blockage of PD-1 has been recognized in the recent research [12].
Although the $V H L$ function loss is a critical factor in the RCC progression, some recent studies have identified the correlation between the VHL mutation and the immune checkpoint molecules. However, only a few studies have established a strong correlation between the VHL mutation and PD-L1 expression. In addition, studies with cell culture experiments have reported that HIF- $2 \alpha$ stabilization, induced by the VHL mutation, together with impaired PVHL increased the PD-L1 expression, suggesting that PD-L1 is a HIF- $2 \alpha$ target, which is upregulated in pVHL-deficient ccRCC $[5,8]$. Furthermore, other studies have emphasized that an increase in the HIF (HIF- $1 \alpha$ or HIF-2 $\alpha$ ) expression is associated with poor prognostic factors and that it might be a potential biomarker $[15,16]$. Notably, the combination of PD-L1 targeting drugs with HIF-inhibiting agents could be an additional option for the treatment of ccRCC.

As HIF- $\alpha$ is essential in tumorigenesis and is one of the primary aims of treatment, especially when the correlation between HIF- $2 \alpha$ and PD-L1 has recently been demonstrated in some cell culture studies, this study aims to investigate the expression condition of PD-L1, HIF- $1 \alpha$ and HIF- $2 \alpha$ proteins in human renal tumor tissues using the immunohistochemical method and assess whether the HIF- $2 \alpha$ or HIF- $1 \alpha$ increases in PD-L1-positive cases. Furthermore, this study aims to determine the correlation between the PD-L1 tumor cell expression and clinicopathological prognostic factors, lymphocyte density displaying PD-1, CD4, and CD8 expression in the tumor microenvironment in ccRCC series.

\section{Methods \\ Patients}

In this study, surgical specimens obtained from 145 patients (males, 93 [64.9\%]; females, 52 [35.1\%]; mean age: $57.8 \pm 11.1$ [range: $31-86$ ] years) with ccRCC who underwent radical or partial nephrectomy between 2007 and 2014 at our institution were retrospectively assessed. While 102 (70.3\%) samples were obtained from patients who underwent radical nephrectomy, 43 (29.7\%) were obtained from those who underwent partial nephrectomy. We analyzed clinical and pathological characteristics, including age, gender, tumor size, WHO/ISUP nucleolar grade [17], coagulative tumor necrosis, microvascular invasion, renal pelvis, adrenal, ureter, renal vein invasion, distant metastasis, and overall survival. Clinicopathological characteristics are summarized in Table 1. This study protocol was approved by the Ethical Committee of Ankara Yıldırım Beyazıt University.

\section{Tissue microarray and immunohistochemistry staining procedure}

Tissue microarray (TMA) blocks using a precision mechanical system (Quick Ray, Manual Tissue Microarrayer, 
Table 1 Summary of the clinical and histopathological characteristics of 145 patients with ccRCC

\begin{tabular}{ll}
\hline Variables & Number of patients \\
\hline Sex & $93(64.9 \%)$ \\
F & $52(35.1 \%)$ \\
Age (years) & $57.8(31-86)$ \\
Tumor size (cm) & $5.76(1.5-18)$ \\
Nucleolar grade & \\
1 & $17(11.7 \%)$ \\
2 & $57(39.3 \%)$ \\
3 & $43(29.7 \%)$ \\
4 & $28(19.3 \%)$ \\
Lymph node metastases & \\
no & $136(93.8 \%)$ \\
yes & $9(6.2 \%)$ \\
Distant metastases & \\
no & $115(79.3 \%)$ \\
yes & $30(20.7 \%)$ \\
Sarcomatoid component & \\
no & $137(94.5 \%)$ \\
yes & $8(5.5 \%)$ \\
\hline
\end{tabular}

UNITMA, Korea) were constructed. From each patient with ccRCC, two tissue samples (diameter, $0.3 \mathrm{~cm}$ each) corresponding to the previously demarcated and most representative areas of respective hematoxylin-eosinstained slides were removed. One of the core biopsies was sampled from the center and the other was sampled from the advancing edge of the tumor. Afterwards, these samples were transferred to a recipient paraffin block at 3-mm intervals. Finally, TMA blocks were cut into $4-\mu \mathrm{m}$ histological sections and used for immunohistochemistry.

An immunohistochemical analysis for the expression of PD-L1 (SP263; 1:100 dilution; Ventana), PD-1 (NAT 105; 1:250 dilution; Cell Marque), CD4 (SP351; 1:100 dilution; Ventana), CD8 (SP57; 1:100 dilution; Ventana), HIF-1 $\alpha$ (H1alpha67; 1:50 dilution; Novus), and HIF-2 $\alpha$ (ep190; 1:100 dilution; GeneTex) were performed. All sections were stained with primary antibodies on Ventana GX benchmark equipment with standard antigen retrieval (CC1 buffer; pH 8.0; Ventana). An ultraView Universal DAB Detection Kit (Ventana) per the manufacturer's instructions were used. In addition, counterstaining was performed as part of the automated staining protocol using hematoxylin. After staining, the slides were washed, dehydrated in graded alcohol and xylene, mounted, and coverslipped. To verify antibody specificity, tonsil tissue was used as a positive control.
The PD-L1 expression in tumor cells in TMAs was quantified. The membranous PD-L1 expression with or without cytoplasmic staining in $\geq 5 \%$ tumor cells was considered positive. In addition, the tumor microenvironment categorization was performed depending on the density of CD4-, CD8-, and PD-1-expressing lymphocytes in the tumor microenvironment. The expression of CD4, CD8, and PD-1 in lymphocytes was scored as 1 point (0-4 cells per high-power field, $\times 400), 2$ points $(5-8$ cells), 3 points (9-12 cells), and 4 points ( $\geq 13$ cells) [18].

For HIF- $1 \alpha$ and HIF- $2 \alpha$, the staining was scored according to the intensity and percentage of tumor cells. The intensity was scored 0 (no staining), 1 (weak), 2 (moderate), and 3 (strong staining). The percentage staining was scored as 0 (no staining), 1 (1-10\%), 2 (11-50\%), 3 (51-90\%), and 4 (91-100\%). In addition, the histoscore was calculated for analysis using the product of these two scores, giving a resultant score from 0 to 12 . The final histoscore used for the data analysis was the mean score from the two tissue cores from each ccRCC tumor block. Finally, the median histoscore was used to evaluate the cutoff scores for "high" or "low" staining for each protein [15].

\section{Statistical analysis}

All patient data were entered to statistical analysis software. Using the Shapiro-Wilk test, the normal distribution of continuous variables was graphically evaluated. In this study, all continuous variables were skewed. Categorical variables (gender, PD-L1 condition, LVI, etc.) to determine identical statistics and the median values to present the number and percentage measurement variables were used. Using the Mann-Whitney $U$-test, differences between continuous variables in accordance with the PD-L1 condition were evaluated. In addition, crosstabs and calculated $\chi^{2}$ values to determine differences between categorical variables in accordance with the PD-L1 condition were created. Next, the time to recurrence was calculated using the Kaplan-Meier method, and the differences between the curves were assessed using the log-rank test. MS-Excel 2010 and the IBM SPSS Statistics 21.0 (released in 2012; IBM SPSS Statistics for Windows, Version 21.0; IBM Corp., Armonk, NY) were used for statistical analyses and calculations. Furthermore, $p<0.05$ was considered statistically significant.

\section{Results}

In this study, the PD-L1 tumor cell expression rates were 0-90\%. While samples with a PD-L1 staining rate of $\geq 5 \%$ were considered positive, those with $<5 \%$ rate were considered negative. Based on the PD-L1 results, 125 (86.2\%) samples were negative, whereas only 20 (13.8\%) were positive. Likewise, samples with scores of 0-2 for PD1, CD4, and CD8 were encoded as "none or mild," whereas scores of 3-4 were encoded as "dense" lymphocytic infiltration in 
the tumor microenvironment. When PD-L1 exhibited positive results, the rate of dense lymphocytic infiltration staining with PD-1, CD4, and CD8 was significantly high $(P<0.05$; Table 2; Fig. 1a-d).

While HIF-1 $\alpha$ was expressed in the nuclei of ccRCC cells, HIF- $2 \alpha$ was expressed in the cytoplasm. Samples with HIF- $1 \alpha$ scores $<3$ were classified as "low," whereas those with $\geq 3$ scores were classified as "high." In contrast, the classification of "low" was used for HIF- $2 \alpha$ scores $<6$, and "high" was used for $\geq 6$. When PDL-1 revealed positive results, the low or high occurrence of HIF-1 $\alpha$ scores was similar $\left(\chi^{2}=0.841 ; p=0.359\right)$. In addition, the rate of high HIF- $2 \alpha$ expression scores was significantly higher in PD-L1-positive cases ( $\mathrm{X} 2=4.636 ; p=0.031$; Table 2; Fig. 1e and $\mathrm{f}$ ). The majority of the cases with scarce PD-L1 expression or no PD-L1 expression showed mild lymphocytic infiltration and low HIF-2 $\alpha$ expression (Figs. 2 and 3).

The results of the PD-L1 tumor cell expression in accordance with the prognostic factors were assessed. When PD-L1-positive cases were compared with the negative ones, no significant difference was observed in terms of most of the prognostic factors $(p>0.05)$. As an exception the rate of WHO/ISUP grade 3-4 tumors was considerably higher in PD-L1-positive cases than that in negative ones (Table 3). Although the mean tumor size was $7.6 \mathrm{~cm}$ in PD-L1-positive cases, it was $5.4 \mathrm{~cm}$ in PD-L1-negative ones; however, this difference was not statistically significant $(p=0.11)$. When cases with PD-1, CD4, CD8 expression scores of $0-2$ were compared with those with scores of 3-4, there was no significant difference in terms of the same prognostic factors $(p>0.05)$. In our study, only 28 cases were grade 4 . Compared with the rest of the cases, grade 4 cases had more dense PD-1 positive lymphocytes in their tumor microenvironments $(p=0.027)$. But there was no statistically significant difference in terms of PDL-1, CD4, CD8, and HIF expressions in grade 4 tumors.

Table 2 PD-1, CD4, CD8, HIF-1a, and HIF-2a expression according to $\mathrm{PD}-\mathrm{L} 1$ results

\begin{tabular}{lllll}
\hline \multicolumn{4}{c}{} & \multicolumn{2}{l}{ PD-L1 Staining } & \multicolumn{1}{l}{ Test Statistics } \\
\cline { 3 - 4 } & & Negative $n(\%)$ & Positive $n(\%)$ & \\
\hline PD-1 & Mild & $92(73.6)$ & $6(30.0)$ & $14.961 ; 0.000$ \\
& Dense & $33(26.4)$ & $14(70.0)$ & \\
CD4 & Mild & $64(51.2)$ & $2(10.0)$ & $11.801 ; 0.001$ \\
& Dense & $61(48.8)$ & $18(90.0)$ & \\
CD8 & Mild & $66(52.8)$ & $2(10.0)$ & $12.682 ; 0.000$ \\
& Dense & $59(47.2)$ & $18(90.0)$ & \\
HIF-1a & Low & $55(44.0)$ & $11(55.0)$ & $0.841 ; 0.359$ \\
& High & $70(56.0)$ & $9(45.0)$ & \\
HIF-2a & Low & $57(45.6)$ & $4(20.0)$ & $4.636 ; 0.031$ \\
& High & $68(54.4)$ & $16(80.0)$ & \\
\hline
\end{tabular}

In this study, the median length of follow-up was 48 months, and the mean survival was 90.06 months for PD-L1-positive cases and 94.9 months for PD-L1-negative cases; this difference was not statistically significant $(p=$ 0.359). There was no significant difference among the cases with PD-1, CD4, CD8 expression scores of $0-2$ and $3-4$ in terms of overall survival $(p<0.05)$.

\section{Discussion}

Studies have reported that the PD-L1 expression is indicative of a response to new PD-1/PD-L1 inhibitors in several tumors, including RCC $[13,19]$. In addition, the clinicopathological and prognostic value of PD-L1 has been investigated in some recent studies and meta-analyses, in which several clinicopathological prognostic factors of renal tumors, such as the WHO/ISUP grade, presence of necrosis, tumor size, TNM stage have been compared with the PD-L1 expression, and a considerable correlation between some of these factors has been determined. In addition, most studies have suggested that patients with intratumoral high PD-L1 expression exhibited aggressive tumors and have increased risk of death from RCC [1, 12, 19-21].

One of the most extensive meta-analysis investigating 1863 patients from 10 studies reported that the PD-L1 expression is correlated with poor overall survival in ccRCC and non-ccRCC. In addition, the PD-L1 expression was highly correlated with the primary tumor stage, regional lymph node metastases, distant metastases, nuclear grade, and tumor necrosis. In this meta-analysis, the PD-L1 expression is determined in 414 cases $(29.5 \%)$ in the ccRCC population [22]. However, we demonstrated that PD-L1 tumor cell expression was $13.8 \%$ in ccRCC cases. The cutoff value used to evaluate PD-L1 positivity were $\geq 5 \%$ in seven out of the 10 studies in the content of this meta-analysis and therefore similar to our study. In fact, the reported rate of the PD-L1 positivity was between 15 and $66 \%$, which is indicative of high variability $[19,20,23]$.

Compared with other studies, the lower rate of the PD-L1 tumor cell expression in this study and the reported rate of high variability in previous studies could be attributed to the use of different anti-PD-L1 antibodies, different cutoff values, and tumor heterogeneity. Of note, ccRCC is a neoplasm characterized by intratumoral heterogeneity [24]. The use of the TMA to indicate the PD-L1 expression in this study could be a pitfall because of tumor heterogeneity. In addition, the PD-L1 expression might vary within the primary tumor or in the primary tumor versus metastases, which might limit the predictive value of this biomarker. Callea et al. reported discordant staining of PD-L1 between primary tumors and corresponding metastases in a high proportion of cases [25]. In this study, PD-L1-positivity correlated with high WHO/ISUP nucleolar grade. Notably, studies investigating the prognostic significance of 


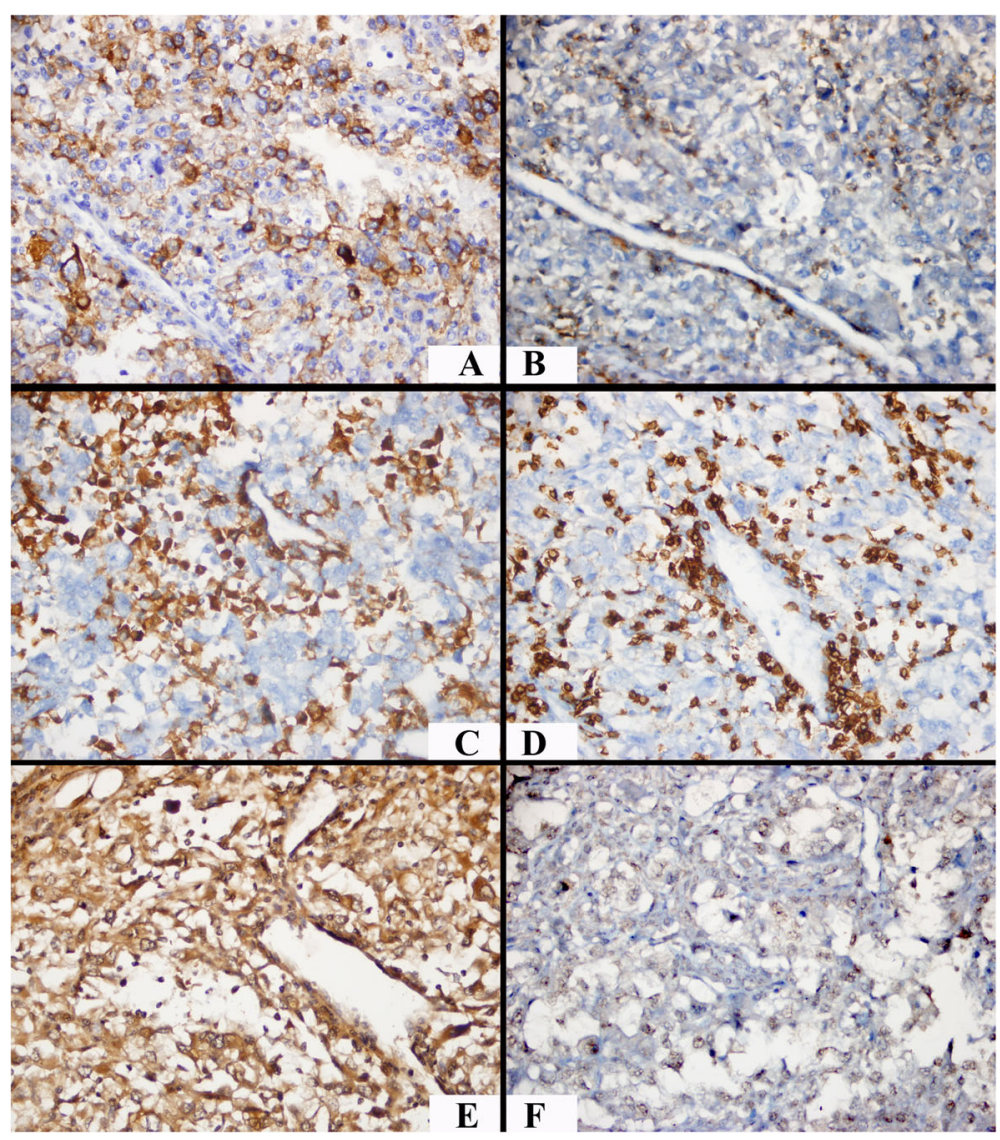

Fig. 1 A PD-L1-positive case with an increased lymphocyte density in the microenvironment and high HIF-2a, low HIF-1a expression ( $\times$ 400). a PD-L1 positivity with prominent membranous and scarce cytoplasmic staining. b PD-1-positive dense lymphocytic infiltration. c CD4-positive dense lymphocytic infiltration. d CD8-positive dense lymphocytic infiltration. e High-score HIF-2a expression. f Low-score HIF-1a expression

PD-L1 are comparatively fewer in RCC, and the results are not entirely consistent $[26,27]$.

Furthermore, ccRCCs harboring the PD-L1 expression significantly correlated with PD-1-, CD4-, and CD8positive dense inflammatory response. In our study, it was demonstrated that, mononuclear cells that infiltrate the RCC tumor microenvironment express PD-1. Thompson et al. reported that patients with PD-1-positive immune cells tended to harbor more $\mathrm{B} 7-\mathrm{H} 1^{+}$tumor cells and larger and higher-grade tumors. In addition, the cancer-specific death rate was considerably higher in patients with PD-1-positive immune cells compared with PD-1-negative ones [14]. Perhaps, interactions between immune cell PD-1 and PD-L1 might promote the cancer progression by contributing to immune dysfunction in patients with ccRCC. Reportedly, immune-regulated tumors exhibited aggressive histological features, a high risk of disease progression, and a $\mathrm{CD} 8^{+} \mathrm{PD}-1^{+}$and $\mathrm{CD} 4^{+}$phenotypic signature [28]. Besides PD-L1, the identification of the lymphocyte density in tumor microenvironment as a prognostic biomarker could facilitate detecting patients who could benefit from the checkpoint blockade.
Hypoxia is crucial for the PD-L1 up regulation. PD-L1 is the B7 family member of immune-regulatory ligands and could be stimulated by hypoxia [29]. This situation has led researchers to investigate whether the PD-L1 expression in ccRCC is due to the deregulation of the pVHL-HIF axis [5]. Loss of the pVHL function causes HIF stabilization acting as a pseudo-hypoxic condition in most ccRCCs. Ruf et al. reported that the PD-L1 up regulation in ccRCC cell lines was determined to be HIF-dependent and driven predominantly by the HIF- $2 \alpha$ subunit, which accumulated in ccRCC because of VHL protein inactivation. In contrast, the knockdown of HIF- $2 \alpha$, but not of HIF-1 $\alpha$, decreased PD-L1 protein levels in ccRCC cell lines [5]. Our study showed a strong association of increased levels of the HIF-2 $\alpha$ expression in PD-L1-positive ccRCC tumor samples by immunohistochemistry, demonstrating the correlation between the increased PD-L1 and HIF expression, suggesting that the regulation of PD-L1 might depend on the HIF expression [5, 8]. Few studies have demonstrated the direct binding of HIF-1 $\alpha$ to a transcriptionally active region in the $\mathrm{PD}-\mathrm{L} 1$ proximal promoter, indicating PD-L1 as a potential target for HIF- $1 \alpha$ 


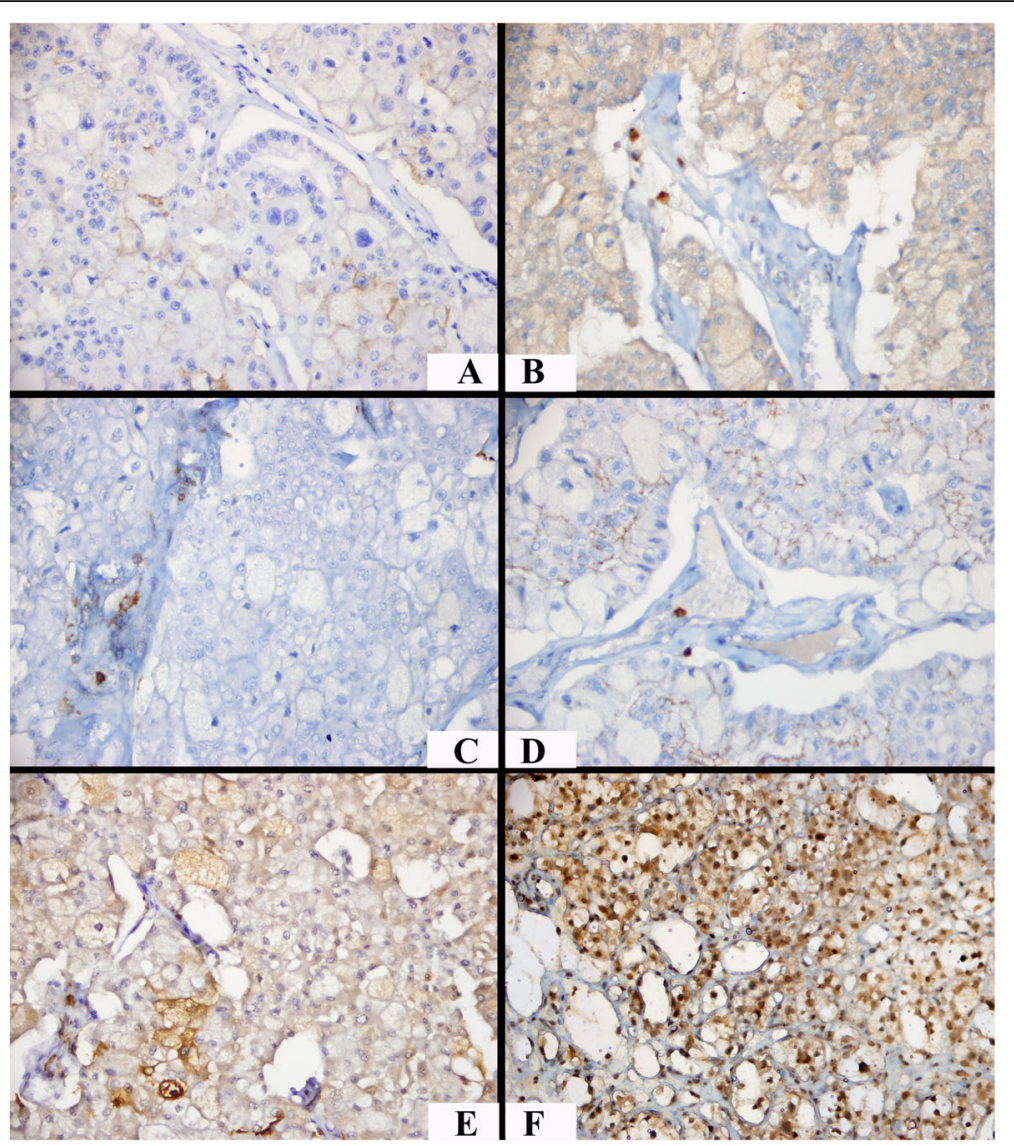

Fig. 2 A case exhibiting PD-L1-expression in a few cells with a mild lymphocyte density in the microenvironment, low HIF-2a expression, and high HIF-1a expression $(\times 400)$. a Scarce incomplete membranous PD-L1 staining. b PD-1-positive mild lymphocytic infiltration, c CD4-positive mild lymphocytic infiltration. $\mathbf{d}$ CD8-positive mild lymphocytic infiltration, e Low-score HIF-2a expression. $\mathbf{f}$ High-score HIF-1a expression

[30]. In our study, there was no association between PD-L1 expression and HIF $1 \alpha$. VHL-defective RCC cells tend to express more HIF- $2 \alpha$ than HIF- $1 \alpha$ protein [4] as the ccRCC progress the HIF-1 $\alpha /$ HIF- $2 \alpha$ balance shifts toward HIF- $2 \alpha$.

Kammerer et al. have found PD-L1 expression to be associated in particular with non-inactivated wild-type $V H L$ tumors [11]. Beuselinck et al. have reported PD-L1 expression and fewer $V H L$ gene mutations in ccRCC4 tumors [31].

These reports suggest that alternative oncogenic pathways in ccRCC may lead to PD-L1 overexpression despite HIF degradation due to the presence of an activated VHL protein. Tumors without the inactivation of VHL could use alternative pathways, such as the MAP kinase and PI3K- AKT-mTOR pathways involved in ccRCC oncogenesis [32].

The emergence of the molecular basis of hypoxia and angiogenesis has enabled the development of treatments toward HIF-related pathways, like phosphatidylinositol 3-kinase-AKT-mTOR, RAS-RAF-MAP, and VEGF signal pathways. Although these agents result in positive recovery without progression, clinical resistance exists. Recently, treatments toward HIF with agents such as histone deacetylase inhibitors and HIF- $2 \alpha$ antagonists have been reported $[33,34]$. Presumably, the revelation that the correlation between the HIF pathway and the immune response is associated with PD-L1 could be useful for the enlightenment of tumor biology. Moreover, there could be more positive results regarding HIF- $2 \alpha$ antagonists, which are yet to be added to immunotherapy.

This study has some limitations. One major limitation of studies reporting PD-L1 staining to date, including this study, is the use of various antibodies and variability in staining methodologies. However, antibody used in our study has recently been approved by FDA. Thus, standardization of staining procedures and scoring methods is warranted before PD-L1 and PD-1 could be widely used as predictive biomarkers [35]. Although recent studies suggest evaluating PD-L1 status in both components (either immune cells or tumor cells), in this study, PD-L1 expression of tumor infiltrating lymphocytes 


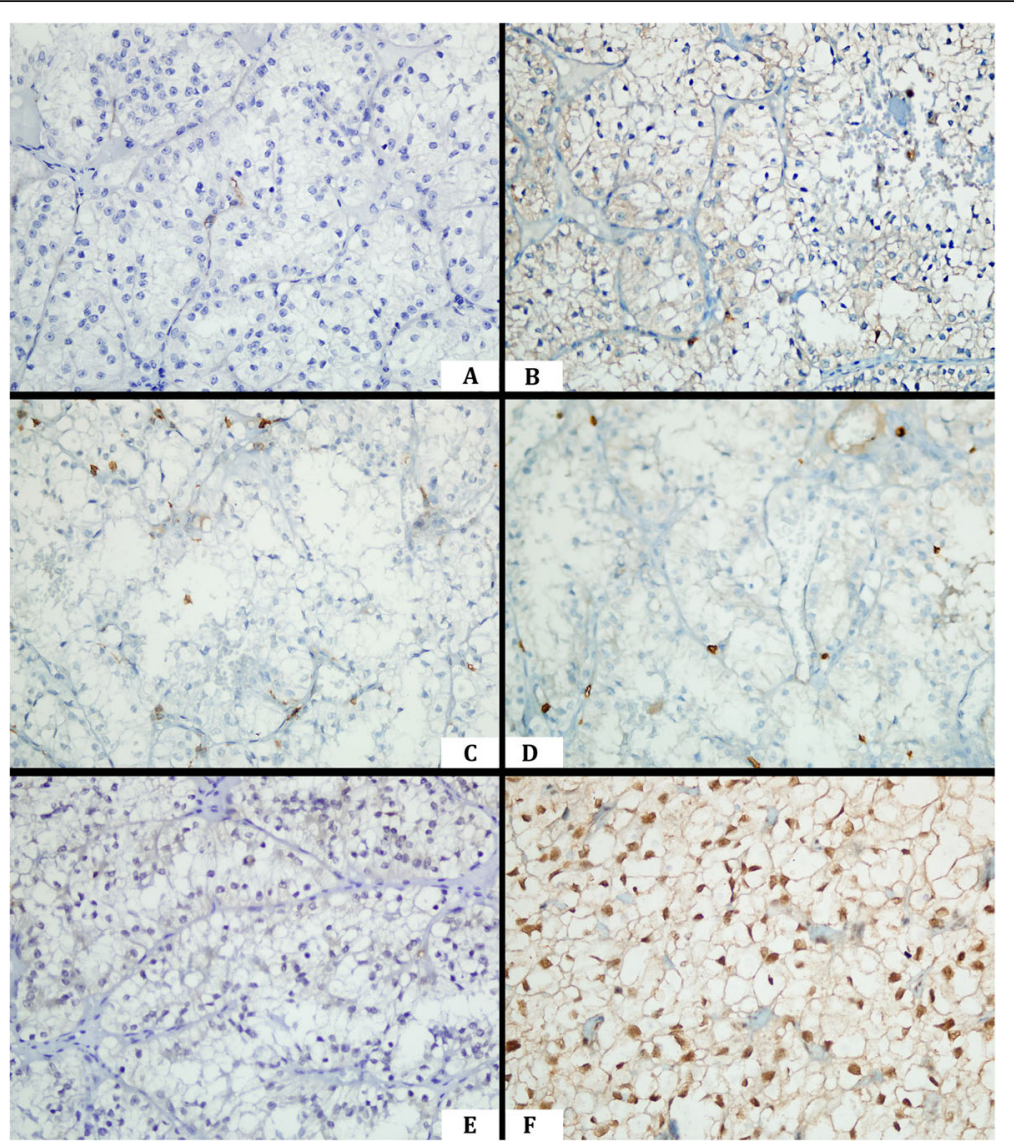

Fig. 3 A PD-L1 negative case with a mild lymphocyte density, low HIF-2a expression, and high HIF-1a expression ( $\times$ 400). a No PD-L1 staining. b PD-1-positive mild lymphocytic infiltration, c CD4-positive mild lymphocytic infiltration. $\mathbf{d}$ CD8-positive mild lymphocytic infiltration, e Negative HIF-2a expression. $\mathbf{f}$ High-score HIF-1a expression

was not assessed [28, 36]. Instead, PD-L1 expression in tumor cells and its interaction with PD-1, CD4, CD8-positive lymphocytes was our center of interest. The use of TMA sections instead of whole sections is another restriction in our study because of tumor heterogeneity. Another limitation of this study was the inability to assess the VHL mutation in patients. However, the HIF expression status reflected the deficient VHL-HIF axis or hypoxia. Since VHL pathway is unperturbed in clear cell papillary RCC, these cases could act as negative controls. However, clear cell papillary RCC cases have not been tested in this study.

Hypoxia considerably increases the PD-L1 expression on macrophages, myeloid-derived suppressor cells, DCs, and tumor cells. HIF-induced tumor cell PD-L1 expression contributes to cancer immune evasion. The blockade of PD-L1 under hypoxia enhances T-cell activation [30]. In addition, blocking the HIF accumulation prevented the hypoxia induced PD-L1 expression and caused resistance to tumor cell lysis mediated by cytotoxic T cells [37]. This suggests that combining therapies blocking PD-1/PD-L1 with agents targeting HIF could further improve the tumor cell clearance by breaking the immune evasion in RCC [5].

\section{Conclusion}

In our study, PD-L1 tumor cell expression was $13.8 \%$ of the ccRCC cases with SP263 clone and it was correlated with higher levels of PD-1, CD4, and CD8. Moreover, PD-L1 expression was associated with high HIF- $2 \alpha$ expression indicating the possibility of PD-L1 regulation by HIF- $2 \alpha$. However, there was no correlation between PD-L1 tumor cell expression and HIF-1 $\alpha$ scores. In PD-L1-positive cases, there was no significant difference in terms of the most of the prognostic factors except for the high WHO/ISUP grade. A patient presenting with a high-grade tumor with dense lymphocytic infiltration can be candidate for PD-L1-targeted therapy. These morphological characteristics may be premonitory for further immunohistochemical tests. There are several suggested mechanisms regulating PD-L1 expression, such as VHL, hypoxia, or other alternative pathways. This study highlights the necessity of 
Table 3 Summary of clinicopathologic prognostic factors according to the PD-L1 status

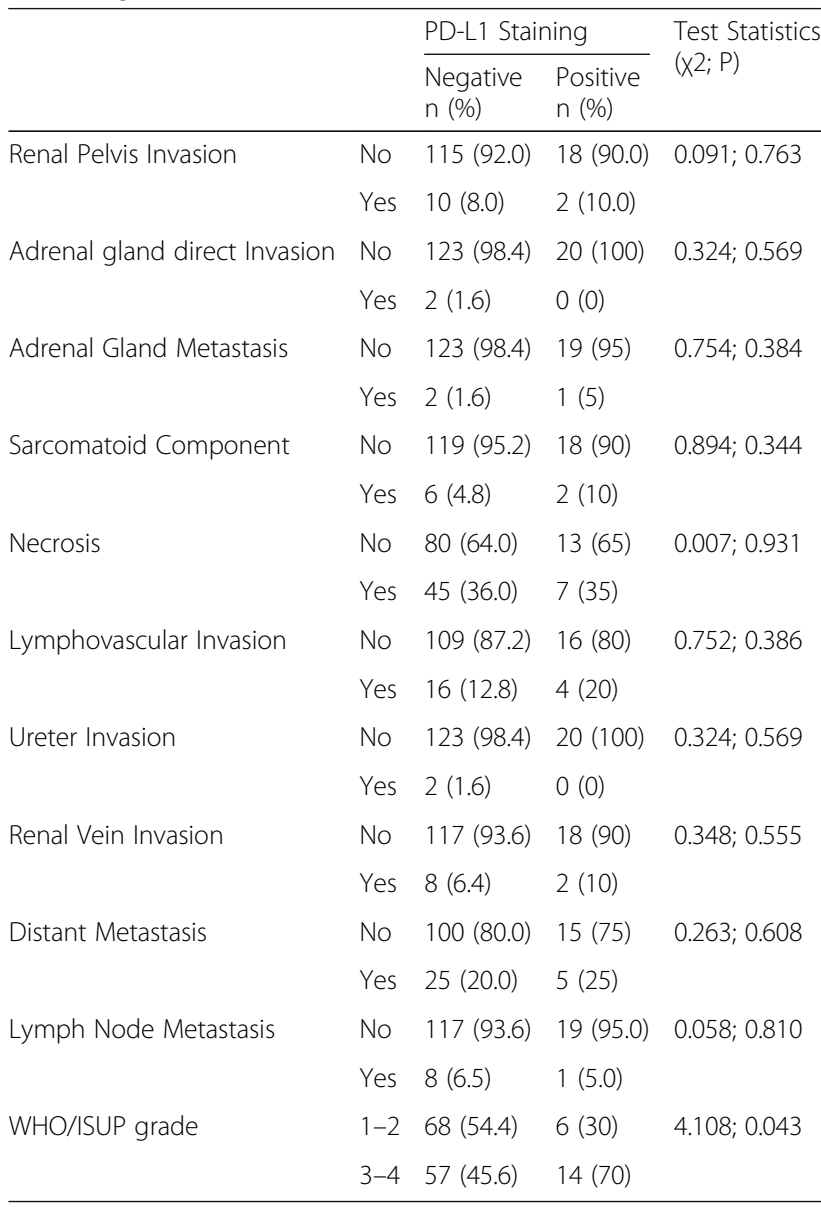

determining biological characteristics of tumors to elucidate the specific correlation between tumor-driving pathways and the immune system and precisely assess the tumor microenvironment to determine predictive biomarkers for the identification of tailored treatment. The interactions between potential biomarkers must be determined accurately, especially when considering the combination treatment.

\section{Abbreviations}

ccRCC: Clear cell renal cell carcinoma; DCs: Dendritic cells; HIF: Hypoxiainducible factor; PD-1: Programmed death 1; PD-L1: Programmed death ligand 1; PD-L2: Programmed death ligand 2; PVHL: von Hippel-Lindau protein; TMA: Tissue microarray

\section{Availability of data and materials}

Data will be available from the authors on reasonable request.

\section{Authors' contributions}

$H T D, B G$, and AK participated in the design of the study. MK performed immunoassays. BB, BY, and MAS participated in coordination and helped in drafting of the manuscript. AFA and AA performed surgical treatment and follow-up of the patients. HTD and MK analyzed the data and drafted the manuscript. All authors have read and approved the final version to be published.

\section{Ethics approval and consent to participate}

This retrospective study was approved by the Ethical Committee of Ankara Yıldırım Beyazıt University (Reference number: 26379996/178). The committee decided that additional informed consent was not required due to the retrospective nature of analysis.

\section{Consent for publication}

Not applicable.

\section{Competing interests}

The authors declare that they have no competing interests.

\section{Publisher's Note}

Springer Nature remains neutral with regard to jurisdictional claims in published maps and institutional affiliations.

\section{Author details}

${ }^{1}$ Faculty of Medicine, Department of Pathology, Ankara Yıldırım Beyazıt University, Ankara, Turkey. ${ }^{2}$ Department of Pathology, Usak University, Education and Research Hospital, Usak, Turkey. ${ }^{3}$ Department of Oncology, Ankara Atatürk Education and Research Hospital, Ankara, Turkey. ${ }^{4}$ Faculty of Medicine, Department of Oncology, Ankara Yıldırım Beyazıt University, Ankara, Turkey. ${ }^{5}$ Faculty of Medicine, Department of Urology, Ankara Yıldırım Beyazıt University, Ankara, Turkey.

Received: 2 April 2018 Accepted: 16 August 2018

Published online: 25 August 2018

\section{References}

1. Xu F, Xu L, Wang Q, An G, Feng G, Liu F. Clinicopathological and prognostic value of programmed death ligand-1 (PD-L1) in renal cell carcinoma: a meta-analysis. Int J Clin Exp Med. 2015;8:14595-603.

2. Frew IJ, Moch H. A clearer view of the molecular complexity of clear cell renal cell carcinoma. Annu Rev Pathol. 2015;10:263-89.

3. Keith B, Johnson RS, Simon MC. HIF1alpha and HIF2alpha: sibling rivalry in hypoxic tumour growth and progression. Nat Rev Cancer. 2011;12:9-22.

4. Raval RR, Lau KW, Tran MG, Sowter HM, Mandriota SJ, Li JL, Pugh CW, Maxwell PH, Harris AL, Ratcliffe PJ. Contrasting properties of hypoxiainducible factor 1 (HIF-1) and HIF-2 in von Hippel-Lindau-associated renal cell carcinoma. Mol Cell Biol. 2005;25:5675-86.

5. Ruf M, Moch H, Schraml P. PD-L1 expression is regulated by hypoxia inducible factor in clear cell renal cell carcinoma. Int J Cancer. 2016;139:396-403.

6. Ishida Y, Agata Y, Shibahara K, Honjo T. Induced expression of PD-1, a novel member of the immunoglobulin gene superfamily, upon programmed cell death. EMBO J. 1992;11:3887-95.

7. Keir ME, Francisco LM, Sharpe AH. PD-1 and its ligands in T-cell immunity. Curr Opin Immunol. 2007;19:309-14.

8. Messai Y, Gad S, Noman MZ, Le Teuff G, Couve S, Janji B, Kammerer SF, Rioux-Leclerc N, Hasmim M, Ferlicot S, et al. Renal cell carcinoma programmed death-ligand 1, a new direct target of hypoxia-inducible Factor-2 alpha, is regulated by von Hippel-Lindau gene mutation status. Eur Urol. 2016:70:623-32.

9. Frigola $\mathrm{X}$, Inman BA, Lohse CM, Krco CJ, Cheville JC, Thompson RH, Leibovich B, Blute ML, Dong H, Kwon ED. Identification of a soluble form of $\mathrm{B} 7-\mathrm{H} 1$ that retains immunosuppressive activity and is associated with aggressive renal cell carcinoma. Clin Cancer Res. 2011;17:1915-23.

10. lacovelli R, Nole F, Verri E, Renne G, Paglino C, Santoni M, Cossu Rocca M, Giglione P, Aurilio G, Cullura D, et al. Prognostic role of PD-L1 expression in renal cell carcinoma. A systematic review and meta-analysis. Target Oncol. 2016;11:143-8.

11. Kammerer-Jacquet SF, Crouzet L, Brunot A, Dagher J, Pladys A, Edeline J, Laguerre B, Peyronnet B, Mathieu R, Verhoest G, et al. Independent association of PD-L1 expression with noninactivated VHL clear cell renal cell carcinoma-a finding with therapeutic potential. Int J Cancer. 2017;140:142-8.

12. Leite KR, Reis ST, Junior JP, Zerati M, Gomes Dde O, Camara-Lopes LH, Srougi M. PD-L1 expression in renal cell carcinoma clear cell type is related to unfavorable prognosis. Diagn Pathol. 2015;10:189.

13. Patel SP, Kurzrock R. PD-L1 expression as a predictive biomarker in Cancer immunotherapy. Mol Cancer Ther. 2015;14:847-56.

14. Thompson $\mathrm{RH}$, Dong $\mathrm{H}$, Lohse $\mathrm{CM}$, Leibovich $\mathrm{BC}$, Blute $\mathrm{ML}$, Cheville JC, Kwon ED. PD-1 is expressed by tumor-infiltrating immune cells and is 
associated with poor outcome for patients with renal cell carcinoma. Clin Cancer Res. 2007;13:1757-61.

15. Biswas S, Charlesworth PJ, Turner GD, Leek R, Thamboo PT, Campo L, Turley $\mathrm{H}$, Dildey P, Protheroe A, Cranston D, et al. CD31 angiogenesis and combined expression of HIF-1alpha and HIF-2alpha are prognostic in primary clear-cell renal cell carcinoma (CC-RCC), but HIFalpha transcriptional products are not: implications for antiangiogenic trials and HIFalpha biomarker studies in primary CC-RCC. Carcinogenesis. 2012;33:1717-25.

16. Fan Y, Li H, Ma X, Gao Y, Chen L, Li X, Bao X, Du Q, Zhang Y, Zhang X. Prognostic significance of hypoxia-inducible factor expression in renal cell carcinoma: a PRISMA-compliant systematic review and meta-analysis. Medicine (Baltimore). 2015;94:e1646.

17. WHO. Classification of Tumours of the Urinary System and Male Genital Organs. 4th edn. Lyon: IARC; 2016.

18. Miyazaki T, Ishikawa E, Matsuda M, Akutsu H, Osuka S, Sakamoto N, Takano S, Yamamoto T, Tsuboi K, Matsumura A. Assessment of PD-1 positive cells on initial and secondary resected tumor specimens of newly diagnosed glioblastoma and its implications on patient outcome. J Neuro-Oncol. 2017:133:277-85.

19. Choueiri TK, Figueroa DJ, Fay AP, Signoretti S, Liu Y, Gagnon R, Deen K, Carpenter C, Benson P, Ho TH, et al. Correlation of PD-L1 tumor expression and treatment outcomes in patients with renal cell carcinoma receiving sunitinib or pazopanib: results from COMPARZ, a randomized controlled trial. Clin Cancer Res. 2015;21:1071-7.

20. Thompson RH, Gillett MD, Cheville JC, Lohse CM, Dong H, Webster WS, Chen L, Zincke H, Blute ML, Leibovich BC, Kwon ED. Costimulatory molecule B7-H1 in primary and metastatic clear cell renal cell carcinoma. Cancer. 2005;104:2084-91.

21. Thompson RH, Kuntz SM, Leibovich BC, Dong H, Lohse CM, Webster WS Sengupta S, Frank I, Parker AS, Zincke H, et al. Tumor B7-H1 is associated with poor prognosis in renal cell carcinoma patients with long-term followup. Cancer Res. 2006;66:3381-5.

22. Wang Z, Peng S, Xie H, Guo L, Cai Q, Shang Z, Jiang N, Niu Y. Prognostic and clinicopathological significance of PD-L1 in patients with renal cell carcinoma: a meta-analysis based on 1863 individuals. Clin Exp Med. 2018;18(2):165-75.

23. Motzer RJ, Escudier B, McDermott DF, George S, Hammers HJ, Srinivas S, Tykodi SS, Sosman JA, Procopio G, Plimack ER, et al. Nivolumab versus Everolimus in advanced renal-cell carcinoma. N Engl J Med. 2015;373:1803-13.

24. Gerlinger M, Rowan AJ, Horswell S, Math M, Larkin J, Endesfelder D, Gronroos E, Martinez P, Matthews N, Stewart A, et al. Intratumor heterogeneity and branched evolution revealed by multiregion sequencing. N Engl J Med. 2012;366:883-92.

25. Callea M, Albiges L, Gupta M, Cheng SC, Genega EM, Fay AP, Song J, Carvo I, Bhatt RS, Atkins MB, et al. Differential expression of PD-L1 between primary and metastatic sites in clear-cell renal cell carcinoma. Cancer Immunol Res. 2015;3:1158-64.

26. Ning XH, Gong YQ, He SM, Li T, Wang JY, Peng SH, Chen JC, Liu JY, Qi NN, Guo YL, Gong K. Higher programmed cell death 1 ligand 1 (PD-L1) mRNA level in clear cell renal cell carcinomas is associated with a favorable outcome due to the active immune responses in tumor tissues. Oncotarget. 2017;8:3355-63.

27. Thompson RH, Gillett MD, Cheville JC, Lohse CM, Dong H, Webster WS, Krejci KG, Lobo JR, Sengupta S, Chen L, et al. Costimulatory B7-H1 in renal cell carcinoma patients: Indicator of tumor aggressiveness and potential therapeutic target. Proc Natl Acad Sci U S A. 2004;101:17174-9.

28. Giraldo NA, Becht E, Vano Y, Petitprez F, Lacroix L, Validire P, Sanchez-Salas R, Ingels A, Oudard S, Moatti A, et al. Tumor-infiltrating and peripheral blood T-cell Immunophenotypes predict early relapse in localized clear cell renal cell carcinoma. Clin Cancer Res. 2017;23:4416-28.

29. Barsoum IB, Koti M, Siemens DR, Graham CH. Mechanisms of hypoxiamediated immune escape in cancer. Cancer Res. 2014;74:7185-90.

30. Noman MZ, Desantis G, Janji B, Hasmim M, Karray S, Dessen P, Bronte V, Chouaib S. PD-L1 is a novel direct target of HIF-1alpha, and its blockade under hypoxia enhanced MDSC-mediated T cell activation. J Exp Med. 2014;211:781-90.

31. Beuselinck B, Job S, Becht E, Karadimou A, Verkarre V, Couchy G, Giraldo N, Rioux-Leclercq N, Molinie V, Sibony M, et al. Molecular subtypes of clear cell renal cell carcinoma are associated with sunitinib response in the metastatic setting. Clin Cancer Res. 2015;21:1329-39.

32. Robb VA, Karbowniczek M, Klein-Szanto AJ, Henske EP. Activation of the mTOR signaling pathway in renal clear cell carcinoma. J Urol. 2007;177:346-52.
33. Baldewijns MM, van Vlodrop IJ, Vermeulen PB, Soetekouw PM, van Engeland M, de Bruine AP. VHL and HIF signalling in renal cell carcinogenesis. J Pathol. 2010;221:125-38.

34. Chen W, Hill H, Christie A, Kim MS, Holloman E, Pavia-Jimenez A, Homayoun F, Ma Y, Patel N, Yell P, et al. Targeting renal cell carcinoma with a HIF-2 antagonist. Nature. 2016;539:112-7.

35. Udall M, Rizzo M, Kenny J, Doherty J, Dahm S, Robbins P, Faulkner E. PD-L1 diagnostic tests: a systematic literature review of scoring algorithms and test-validation metrics. Diagn Pathol. 2018;13:12.

36. Zhu J, Armstrong AJ, Friedlander TW, Kim W, Pal SK, George DJ, Zhang T. Biomarkers of immunotherapy in urothelial and renal cell carcinoma: PD-L1, tumor mutational burden, and beyond. J Immunother Cancer. 2018;6:4.

37. Barsoum IB, Smallwood CA, Siemens DR, Graham CH. A mechanism of hypoxia-mediated escape from adaptive immunity in cancer cells. Cancer Res. 2014;74:665-74.

\section{Ready to submit your research? Choose BMC and benefit from:}

- fast, convenient online submission

- thorough peer review by experienced researchers in your field

- rapid publication on acceptance

- support for research data, including large and complex data types

- gold Open Access which fosters wider collaboration and increased citations

- maximum visibility for your research: over $100 \mathrm{M}$ website views per year

At BMC, research is always in progress.

Learn more biomedcentral.com/submissions 